\title{
ESPAÑA Y FRANCIA EN EL SUR DE MARRUECOS: INTERESES, DELIMITACIÓN DE FRONTERAS Y CONTENCIOSO TERRITORIAL, 1900-1912
}

\author{
JESÚS MARÍA MARTÍNEZ MILÁN
}

Facultad de Economía, Empresa y Turismo

\section{Introducción}

Este artículo tiene por objeto analizar las complejas y convulsas relaciones que mantuvieron los gobiernos de París y Madrid en el marco de las conversaciones encaminadas a delimitar las fronteras de sus respectivas zonas de influencia en el sur de $\mathrm{Ma}-$ rruecos. El origen de los intereses de ambas potencias en los confines del reino cherifiano se remonta a la segunda mitad del siglo XIX; en esos años, las relaciones entre España y Francia atravesaron por un periodo de desconfianza mutua que estuvo marcado por los intentos franceses de intervenir en la región aprovechando el descontento de las tribus. Tras la tempestad se hizo la calma y, en los albores del siglo xx, la tensión entre ambos países en la zona volvió a sus cauces normales con la firma, en 1900, del tratado sobre Río de Oro y Guinea.

Después de un paréntesis de dos años, que culminó en 1902 con el fracaso de las conversaciones entre Francia y España para alcanzar un acuerdo de delimitación de fronteras en Marruecos, la situación dio paso a un periodo de tensión diplomática que se agudizó a partir de 1904, como consecuencia de la cada vez mayor injerencia gala en la zona de influencia española. Esta situación, que se tornó preocupante después de la conferencia de Algeciras, en 1906, quedó “cortocircuitada" con la llegada de la

Este artículo fue recibido por la dirección de la revista el 14 de enero de 2014 y aceptado para su publicación el 24 de febrero de 2014. 
cañonera alemana Panthersprung al puerto de Agadir en el verano de 1911.

Tras las conversaciones franco-alemanas - que culminaron con la firma de un convenio entre ambos países en el otoño de ese año, por el que Berlín dejaba a Francia vía libre en Marruecos a cambio de la obtención de territorios en el África ecuatorial francesa-, París y Madrid sellaron, en 1912, el definitivo desmembramiento del reino alauita. En relación con el sur de Marruecos, España no sólo sufrió una merma en el espacio geográfico que se le asignaba en 1902, sino también la ruptura de la continuidad territorial entre sus colonias de Ifni y el Sahara occidental, por un lado, y la zona sur del protectorado (Tarfaya) por el otro.

\section{Los antecedentes de los recelos españoles hacia Francia en el sur de Marruecos en el último cuarto del siglo XIX}

Si exceptuamos el temor que despertó en la clase política de la Restauración el doble emplazamiento de factorías inglesas en Canarias y en la costa sahariana en el último cuarto del siglo XIX, sólo Francia logró concitar más recelos en los gobiernos liberales y conservadores de la época. ${ }^{1} \mathrm{El}$ primer ejemplo de esta desconfianza se remonta a la sublevación de las tribus del Sūs ${ }^{2}$ y los contactos del sherif ${ }^{3}$ de Tazeroualt, Sidid Husein ben Hachem, y su hijo, Sidi Mohamed, con los franceses en la segunda

\footnotetext{
${ }^{1}$ Sobre esta cuestión, véase Jesús María Martínez Milán, “Los establecimientos y proyectos extranjeros en la costa de África frontera a Canarias en el último cuarto del siglo XIX, y los intereses españoles en la zona”, en Hassan Bagri y Antonio Tejera Gaspar (coords.), Marruecos y Canarias. Miradas cruzadas, Rabat, Publicaciones de la Facultad de Letras y Ciencias Humanas de la Universidad Ibn Zohr, 2000, pp. 153-169.

${ }^{2}$ Las tribus (sing. qabila, plur. qabaīl) del Sūs estaban integradas por los berberófonos: Ayt Massat, Ayt Azarar, Ayt Ba 'Amran, Ayt Akhsas, Tazeroualt, y por otras tribus arabófonas seminómadas ubicadas en la región del Nūn. Este conjunto tribal estaba encuadrado en dos leff o sistemas de alianzas opuestos: los Guezzoula y los Tahogat. Los tres pilares sobre los que se asentaba la alianza de los Guezzoula estaban constituidos por las casas de Iligh, Tamanart y Bairūk, en Goulimine. Véase Alfred Le Chatelier, Tribus du sud-ouest marocain. Bassins côtiers entre Sous et Draa, París, Ernest Laroux, 1891, pp. 20-54, y Paul Pascon y Mohamed Ennaji, Le Makbzen et le Sous AlAqsa. La correspondance politique de la maison d'Iligh (1821-1894), París-Casablanca, CNRS-Toukbal, 1988, pp. 25-27.

${ }^{3}$ Descendiente del profeta Mahoma (plur.: shorfa).
} 
mitad del decenio de los ochenta del siglo XIx. Sabemos que las causas de la rebelión de las cabilas no se reducían solamente a cuestiones puramente fiscales. ${ }^{4}$ Desde el advenimiento de Mulay Hassan I, en 1873, el Majzén (administración central) había puesto en marcha una política que consistía en "reinsertar" al Sūs en la organización común de las provincias marroquíes, en unas condiciones coyunturales nada fáciles, como muy bien han descrito Paul Pascon y Mohamed Ennaji, por un lado, y Mustapha Naimi, por el otro. ${ }^{5}$

${ }^{4}$ En su análisis sobre Marruecos, la literatura colonial dividió el país en dos zonas bien diferenciadas. Por un lado, bilad al-Majzen (territorio sometido a la autoridad del gobierno) y, por el otro, bilad al-Siba (territorio que escapa al control del gobierno). El concepto de Siba (disidencia o revuelta) fue utilizado así para justificar la política colonial; sin embargo, esa división no se ajustaba a la realidad. El Marruecos precolonial era un Estado que se asentaba sobre tres estructuras de poder que coexistían: el sistema tribal, los linajes o clanes religiosos y el Majzén. En opinión de Ernest Gellner, las tribus formaban una sociedad segmentaria de filiación patrilineal, caracterizada por el equilibro entre sus segmentos, la acefalia y el igualitarismo. Para que esta sociedad segmentaria "laica" funcionara era necesario el papel de equilibrio que jugaban los linajes santos (zawiya o cofradía) sobre las tribus. En tanto que descendientes del profeta, estos linajes religiosos eran tan respetados por las tribus laicas que les permitían llevar la administración de sus asuntos. Al igual que en otras partes del reino cherifiano, las tribus del Sūs y del Nūn sólo reconocían la autoridad religiosa del sultán, y rechazaban la autoridad y el papel de los representantes del Majzén, en especial cuando concurrían una serie de factores, tales como: crisis de subsistencia e incremento de los precios de los alimentos básicos, la excesiva presión fiscal o la tiranía de los agentes de la autoridad central. En ese momento, las tribus entraban en disidencia y se revelaban contra el poder del Majzén. En su papel de máxima autoridad religiosa, la estrategia del sultán consistía entonces en buscar la sumisión de esas tribus por medio de la fuerza o de alianzas políticas. Véase Ernest Gellner, Saints of the Atlas, Londres, Weidefeld \& Nicolson, 1969, pp. 45-68; Ernest Gellner y Valensi Lucette, "Pouvoir politique et fonction religieuse dans l'Islam marocain”, Annales. Economies, Sociétés, Civilisations, núm. 3, 1970, pp. 699-713; Ernest Gellner, Cultura, identidad y política. El nacionalismo y los nuevos cambios sociales, Barcelona, Gedisa, 2003, pp. 40-57; David M. Hart, Estructuras tribales precoloniales en Marruecos Bereber, 1860-1933: una reconstrucción etnográfica en perspectiva histórica, Granada, Universidad de Granada, 1997; Pascon y Ennaji, Le Makbzen et le Sous Al-Aqsa, op. cit., pp. 29-30, y Mustapha Naimi, "Le pouvoir Makhzen dans le Souss", Revue Maroc Europe. Histoire, Economies, Sociétés, núm. 6, 1994, pp. 85-94.

${ }^{5}$ Pascon y Ennaji, Le Makbzen et le Sous Al-Aqsa, op. cit., pp. 9-30. Mustapha Nai$\mathrm{mi}$, "La rive sud saharienne de 1842 à 1872 dans les registres comptables de la famille Bayruk (l'apport de trois nouvelles sources)", ponencia presentada en el Colloque sur les Sources Arabes de l'Histoire Africaine, Commission Internationale pour une Histoire Scientifique et Culturelle de l'Humanité, Rabat, 1-3 de abril de 1987, s.1., Commission for a Scientific and Cultural History of Mankind, 1987, y Mustapha Naimi, La dynamique des alliances ouest-sahariennes : de l'espace géographique à l'espace social, París, Maison de Sciences de l’Homme, 2004. 
Entre 1884 y mediados de 1886, el consulado español en Mogador había seguido muy de cerca la sublevación de algunas cabilas del Sūs y, en menor medida, de la región del Nūn, dirigidas por Sidi Husein ben Hachem, no sólo por las sublevaciones en sí, sino por los contactos que este último mantenía con el cónsul francés en Sawīra (Mogador). ${ }^{6}$ Una vez fallecido éste, Hassan I nombró a su hijo, Sidi Mohamed ben Husein ben Hachem, como uno de sus gobernadores en la región. A finales de agosto de 1886 estalló una nueva revuelta, apoyada por Sidi Mohamed, quien perseguía los mismos objetivos que su padre: la independencia económica del Sūs; al mismo tiempo estrechó aún más las relaciones con los franceses. Prueba de ello fue la propuesta que hizo llegar, en septiembre de ese año, al representante francés en Mogador: que la declaración de independencia del Sūs coincidiera con la proclamación, por Francia, del protectorado sobre esa región. Desde el consulado español en dicha ciudad se opinaba que si "el Sultán, sin pérdida de tiempo, no envía contra el á un poderoso ejército y se apodera de él y de su hermano [...] es muy factible se separe él Sūs del Imperio de Marruecos, como de público se dice en aquella comarca, y los franceses se enseñorearan en él y rodearán a Marruecos con una faja de hierro". A principios de 1887, el hijo de Husein seguía adelante con sus planes de "dominar" todo el Sūs. A finales de enero, Antonio Fierro, cónsul de España en Mogador, ${ }^{7}$ informaba que lo controlaba todo, excepto la ciudad de Tiznit, la cabila de Štuka y la fracción Ait Bubker de la tribu Ait Ba 'Amran, en Ifni. ${ }^{8}$

${ }^{6}$ Jesús M. Martínez Milán, "El colonialismo español en el Sáhara occidental y en la zona sur del protectorado español en Marruecos, 1885-1945", tesis de doctorado en historia contemporánea, Madrid, Universidad Nacional de Educación a Distancia, 2000, vol. I, pp. 95-100.

${ }^{7}$ Archivo General de la Administración Pública del Estado (en adelante AGAP), sección África, Marruecos, caja 61, exp. 3, despacho reservado sin número, El cónsul de España en Mogador (Antonio Fierro) a Ministro plenipotenciario de España en Marruecos, Mogador, 11 de octubre de 1886 (las itálicas figuran en el texto). Ibid., 21 de enero de 1887, y Martínez Milán, “El colonialismo español...”, op. cit., p. 100.

${ }^{8} \mathrm{La}$ confederación de los Ayt Ba 'Amran estaba formada por seis tribus o clanes berberófonos (Ayt 1-Khums, Ayt n-Nuss, Ayt Ikhlif, Imsten, Ayt 'Abdallah y Ayt Y'azza) y una tribu nómada arabófona (Isbuya). El ancestro epónimo, Ba 'Amran, tuvo un hijo, Yihya Ba 'Amran, que a su vez tuvo dos hijos (Bubkir Yihya y Baha u-Yihya). Las tribus Ayt n-Nuss, Ayt Ikhlif e Imstiten se consideran descendientes de Bubkir Yahya. Cuando el escrito del cónsul menciona a los “Ait Bubker", hace referencia a 
En un artículo reciente, Pastor Garrigues afirma que las "necesidades de defensa de Canarias impusieron la creación en el consulado de Mogador [...] de un servicio secreto [que] tenía como puntales máximos al intérprete Cristóbal Benítez y al agente indígena El-Morabet”. Para este autor, la necesidad de defender las islas ante la posibilidad de una independencia del Sūs y del Nūn y su conversión en protectorado francés era más que probable. ${ }^{9}$ Sin dejar de ser cierto que el consulado español en Mogador conocía a la perfección los planes franceses entre 1884 y 1889 , afirmar que un posible protectorado francés en el espacio Sūs-Nūn amenazaría la seguridad del archipiélago canario, nos parece, cuanto menos, un poco exagerado, ya que en la propuesta que realizó el propio Sidi Mohamed al cónsul francés, en septiembre de 1886, no se incluía a la región del Nūn. París aceptó el envite siempre que el hijo de Sidi Husein se alzara contra el sultán y proclamara la independencia de la comarca. Para ello, era necesario que todas las cabilas estuvieran de acuerdo con él, de ahí sus prisas por recuperar el prestigio de Iligh entre las tribus de la región. ${ }^{10}$

Los contactos entre el consulado francés en Mogador, a través de su vicecónsul Yacquety, y Sidi Mohamed se intensificaron a lo largo de 1887 y 1888 . A mediados de ese último año, el hijo de Sidi Husein barajaba dos opciones: la carta del Majzén o la independencia a través de los franceses, sin decantarse claramente por ninguna. A principios de 1889, la situación en el Sūs comenzó a deteriorarse una vez más, al tiempo que arreciaban las presiones francesas para que tomase partido por la sublevación. Sin embargo, el temor de Mohamed ben Husein a que el sultán organizara otra expedición al Sūs, unido a una nueva oleada de enfrentamientos entre tribus y a la contestación de

estas tres tribus que habitaban la zona norte del territorio de Sidi Ifni. Véase David M. Hart, "The Ait Ba 'Amran of Ifni: An Ethnography Survey", Revue de l'Occident musulman et de la Méditerranée, núm. 15-16, 1973, pp. 61-74.

${ }^{9}$ Francisco M. Pastor Garrigues, "Marruecos, campo de batalla de los imperialismos europeos en el siglo XIX: la guerra de espías franco-española en el Sūs en 1886-1887", A wrāq. Estudios sobre el mundo árabe e islámico contemporáneo, vol. xxv, 2008, pp. 143-150.

${ }_{10}$ AGAP, África, Marruecos, caja 61, exp. 3, despacho reservado sin número, El cónsul de España en Mogador a Ministro Plenipotenciario de España en Marruecos, Mogador, 4 de abril de 1887, y Martínez Milán, "El colonialismo español...”, op. cit., p. 101. 
la autoridad de Iligh, dio lugar a que el hijo de Sidi Husein desechase la idea de sublevarse contra Muley Hasan. Con ello, el proyecto francés de proclamar el protectorado sobre el Sūs quedó abortado. ${ }^{11}$

En medio de las presiones galas sobre Sidi Mohamed, plenipotenciarios españoles y franceses se reunieron en una conferencia bilateral en París, en marzo de 1886, para dilucidar, al filo de lo convenido en la conferencia de Berlín, la delimitación de la frontera meridional de Río de Oro y todo lo referente al contencioso de Guinea. La comisión mixta inició las sesiones de trabajo tratando, en primer lugar, la delimitación de la posesión de Senegal con el protectorado de Río de Oro. ${ }^{12}$ Mientras Francia intentaría delimitar lo más arriba posible con el fin de ganar en hinterland, España trataría de mantener incólume la costa que daba acceso a las riquezas haliéuticas del banco pesquero y refugio a los pescadores canarios. Tras seis meses de negociaciones, los representantes de ambos países adoptaron de común acuerdo la siguiente delimitación: dividiendo la península de cabo Blanco en dos partes (el oeste para España y el este con la bahía del Galgo para Francia), la línea de demarcación subiría en dirección norte hasta alcanzar el paralelo $21^{\circ} 20^{\prime}$ de latitud norte, "continuando hacia el interior a lo largo de dicho paralelo". En las aguas de la bahía del Galgo, así como en su orilla, los pescadores españoles podrían seguir faenando y realizando todo tipo de operaciones relacionadas con su actividad; por último, se convino que una comisión técnica determinaría, sobre el terreno, la posición exacta de la frontera, al tiempo que se decidió que el acuerdo no sería definitivo hasta que no finalizaran las negociaciones sobre los territorios en litigio del golfo de Guinea.

Entre 1886 y 1891, los representantes de ambos países continuaron de forma intermitente las conversaciones sobre el Muni y sus inmediaciones sin lograr acuerdo alguno. Cuando en junio de ese último año se interrumpió la conferencia, los

${ }^{11}$ Ibid., pp. 102-106.

${ }^{12}$ AgAP, Africa, Marruecos, caja 381, exp. 6, Informe de la Sección Política del Ministerio de Estado, Madrid, 26 de marzo de 1900. Este informe aparece íntegramente reproducido en Tomás García Figueras, La acción africana de España en torno al 98 (1860-1912), Madrid, CSIC, vol. II, pp. 25-29. 
representantes franceses intentaron dar forma diplomática a lo acordado sobre cabo Blanco, presentando un proyecto de convenio en el que se suprimía cualquier referencia al desplazamiento de la línea fronteriza hacia el interior del continente por el paralelo $21^{\circ} 20^{\prime}$; modificación que no fue aceptada por la comisión española. Esta tentativa francesa de recortar la frontera meridional de Río de Oro se explica por el temor que despertaron los acuerdos de Iyîl en el naciente lobby colonial del vecino país. Acuerdos que, aunque el gobierno español no había comunicado - ni lo haría- a las potencias signatarias de la Conferencia de Berlín, podían, en futuras conversaciones bilaterales, repercutir negativamente en la construcción de un bloque africano francófono que uniera sus posesiones del norte de África con las de la parte occidental del continente. En este sentido, Francia había dado el primer paso el 5 de agosto de 1890, con la firma de un convenio con el Reino Unido por el cual Londres dejaba las manos libres en el Sáhara a París para llevar a cabo esa unión a través del lago Chad. ${ }^{13}$

Cuando los contactos sobre esta cuestión volvieron a retomarse, el edificio colonial francés en el África subsahariana estaba prácticamente terminado, habiéndose llevado a cabo la unión con sus posesiones del norte a través del lago Chad. En abril-mayo de 1899, el nuevo jefe del gabinete conservador, Silvela, planteó al embajador francés en Madrid, Patenôtre, la posibilidad de una entente con Francia y Rusia que el propio Delcassé, ministro de Asuntos Exteriores, descartó “por falta de claridad y de perspectiva”. ${ }^{14}$ Sin embargo, una vez que Delcassé concluyó acuerdos con aquellas potencias que podían tener intereses en África del norte, eliminando así los obstáculos a sus ambiciones marroquíes, ordenó a su embajador en Madrid transmitir a Silvela su deseo de arreglar la cuestión de los litigios territoriales del África noroccidental y ecuatorial. La segunda, y definitiva, ronda de conversaciones comenzó a principios de 1900. En lo atinente a Río de Oro, la idea tanto de Delcassé

${ }^{13}$ Jesús M. Martínez Milán, España en el Sáhara occidental y en la zona sur del protectorado en Marruecos, Madrid, UNED Ediciones, 2003, pp. 190-192.

${ }^{14}$ Jean-Marc Delaunay, Méfiance Cordiale. Les relations coloniales franco-espagnoles de la fin du XIX siècle à la Première Guerre mondiale, París, L'Harmattan, 2010, vol. 2, p. 112. 
como de Decrais, ministro de colonias, era conceder a España satisfacciones territoriales en el golfo de Guinea a cambio de territorios en el interior de Río de Oro; sin embargo, se encontraron con la sorpresa de que España reclamaba el Adrār Tmar como parte de la colonia basada en los tratados de Iyîl. Arguyendo que Francia no podía abandonar una comarca que acababa de conquistar, los responsables franceses se prepararon para utilizar un argumento étnico y político que invalidara el tratado. Cansado de la negativa, el gobierno español aceptó la propuesta francesa y despejó el camino para alcanzar un acuerdo global sobre Río de Oro y Guinea. La firma del convenio franco-español sobre ambos territorios se firmó, en París, el 27 de junio de 1900; no satisfizo ni a la opinión pública de los dos países ni al propio gobierno español. ${ }^{15}$

\section{Francia propone... y al final dispone: el controvertido proceso de delimitación fronteriza de las posesiones españolas del sur de Marruecos y el contencioso territorial franco-español en la región, 1900-1912}

El malestar y el temor del gobierno de Silvela porque Francia no quiso aceptar delimitar la frontera norte de Río de Oro en el convenio hispano-francés de 1900, y reconocer la marroquinidad de la Saqīa al Hamrā y Tarfaya, llevó al presidente del Consejo de Ministros español a reconsiderar su política exterior

${ }^{15} \mathrm{El}$ texto del tratado es fiel reflejo de las estrategias seguidas por ambos países en función de su peso político en el orden internacional. Desde 1875, la estrategia seguida por una potencia media como España consistió en asegurar la explotación del caladero sahariano y en mantener la política del statu quo en el reino de Marruecos. Las razones hay que buscarlas en el escaso peso que tuvo esa zona en la política exterior de los primeros gobiernos de la Restauración, si lo comparamos con el peso que tuvieron las colonias del Caribe, las del Pacífico o los enclaves africanos del norte de Marruecos. Sin embargo, para una gran potencia como Francia, el convenio significó despejar los obstáculos que se oponían a sus pretensiones de unir las posesiones del África occidental con las del Magreb. Véase Rosario de la Torre del Río, "El factor colonial en la política exterior española 1789-1898”, en I Encuentro Peninsular de Historia de las Relaciones Internacionales, Zamora, Asociaçao Portuguesa de Historia das Relaçoes Internacionales-Comisión Española de Historia de las Relaciones Internacionales-Fundación Rei Afonso Henriques, 1998, pp. 245-264; Martínez Milán, España en el Sáhara occidental..., op. cit., pp. 196-204, y Delaunay, Méfiance Cordiale..., op. cit., vol. 2, pp. 111-116. 
con objeto de garantizar los intereses de España; o sea, evitar a toda costa que cualquier otra nación (léase Francia) se estableciera entre la frontera sur del reino de Marruecos y la colonia de Río de Oro, con el fin de salvaguardar la seguridad de las islas Canarias. Unos meses antes de que se firmara el susodicho convenio, el gobierno conservador planteó a su homólogo cherifiano la posibilidad de renunciar a Ifni a cambio de Tarfaya, utilizando como argumento un posible plan francés para ocupar el territorio al sur del Uād Drā. Como el fin justifica los medios, Madrid buscó incluso el apoyo del Reino Unido. En el primer contacto con lord Salisbury, el embajador español en Londres, Duque de Mandas, intentó convencerlo de que su gobierno no dificultase las negociaciones que el representante español iba a comenzar con el país alauita, en un momento en el que Gran Bretaña estaba más pendiente de la guerra en Sudáfrica y de los problemas en China. Tras una primera negativa del mandatario británico, el 26 de junio de 1900, lord Salisbury notificaba a Madrid que no tenía inconveniente alguno en que España intentara la permuta de Ifni por Tarfaya. Esta "veleidad sahariana" de Silvela, como la ha calificado Pastor Garrigues, no era sino "la vertiente en política exterior de lo que constituía el 'regeneracionismo’ aplicado por el jefe de los conservadores en la política interior". Sin embargo, la administración de Mulay Abd el Aziz se negó a dicho trueque. Lejos de desfallecer, Silvela inició, en septiembre, conversaciones tanto con el Reino Unido como con otras potencias, incluida Francia, para convencerlas de que presionaran al sultán a fin de que aceptara la propuesta de cambio. Un mes más tarde, el ministro plenipotenciario inglés en Tánger, Arthur Nicolson, argumentó que su país no era favorable a la permuta porque la tesis de la ocupación francesa no tenía sentido, dada la pobreza de la región y la hostilidad de las tribus. Ante la negativa británica, el gobierno conservador se dirigió a Teophile Delcassé, en octubre, buscando ahora el apoyo del vecino septentrional a sus pretensiones sobre Tarfaya. ${ }^{16}$

A finales de 1900, el embajador español en París, León y Castillo, y Delcassé tuvieron los primeros contactos informales

${ }^{16}$ Francisco M. Pastor Garrigues, "Las veleidades saharianas del gobierno Silvela (1900)”, Mélanges de la Casa de Velázquez, tomo 41-1, 2011, pp. 211-231. 
para tratar sobre la frontera septentrional de Río de Oro. El tema de conversación que abrió estos primeros encuentros fue la región de la Saquīa al-Hamrā. Al igual que Silvela, León y Castillo no deseaba que "en aquella región [...] quedase abierto un portillo a futuros peligros”. El embajador acudió a Madrid con objeto de que el jefe del gabinete conservador le diera permiso para iniciar las negociaciones, pero se encontró con el asentimiento del presidente sólo para escuchar a Delcassé. La llegada al poder de los liberales, en la primavera de 1901, fue el pistoletazo de salida a las negociaciones con Francia sobre Marruecos. Entre esa fecha y el otoño de 1902 -y tras arduas negociaciones-, ambos negociadores habían pergeñado un tratado, compuesto de una introducción, once artículos y dos anejos referentes a las respectivas esferas de influencia en el reino alauita. En lo que respecta a la zona meridional, España conseguía una zona de influencia que abarcaba desde la mitad sur del valle del Sūs hasta la Saqīa al-Hamrā. Ahora bien, ¿por qué el tratado de 1902 se convirtió en un tratado nonato? Hasta ahora la historiografía española que ha abordado el tema ha buscado la causa en el cambio de gobierno de los partidos de turno y la negativa de los conservadores a firmarlo porque la garantía francesa no era suficiente. Pastor Garrigues, por su parte, apunta en su tesis doctoral la hipótesis de que no se firmó por “el exceso de celo de León y Castillo". Para ello se ha basado no sólo en los tres despachos oficiales que recibió el embajador español del gobierno liberal autorizándolo para que firmara en noviembre de 1902 —entre ellos, un telegrama con la palabra en clave "Guadalajara", que significaba el plácet para su firma-, sino además en la negativa de León y Castillo a rubricar el acuerdo ante una serie de "pequeños cambios", solicitados por Francia, que afectaban el artículo III, sin tener el visto bueno de Madrid. Cuando el documento modificado con los planos preceptivos llegó a la capital de España, coincidió con el cambio del gobierno liberal por el del partido conservador, con Silvela nuevamente al frente. ${ }^{17}$ En este sentido, Antonio Niño sostiene

\footnotetext{
${ }^{17}$ Francisco M. Pastor Garrigues, “España y la apertura de la cuestión marroquí (1897-1904)", tesis de doctorado, Valencia, Universidad de Valencia-Servei de Publicacions, 2006, pp. 1163-1170; Francisco M. Pastor Garrigues, “Antonio Maura y el papel del II Reich en las negociaciones francesas sobre Marruecos de 1903-1904”, Pasado y Me-
} 
que Silvela se negó a firmarlo porque quería sacar a España del aislamiento internacional mediante una alianza con Francia que fuera más allá de la cuestión de Marruecos. ${ }^{18}$ Jean-Marc Delaunay, por su parte, afirma que la palabra utilizada como clave para firmar el tratado jamás llegó a León y Castillo, y apuesta que fueron los propios franceses quienes no quisieron firmar. Justo antes de que el embajador español acudiera al Quai d'Orsay (sede del Ministerio de Asuntos Exteriores de Francia) para el acto en cuestión, el jefe del Estado Mayor del Ejército, general Pandézec, consideró inaceptable la redacción del tratado porque las delimitaciones previstas rompían toda esperanza de una unión fácil entre Argelia y el litoral atlántico de Marruecos. De ahí que Delcassé rechazara la firma "alegando un posible cuestionamiento de la división de zonas”. En realidad -concluye Delaunay-, las reticencias españolas sirvieron de alguna manera de excusa al rechazo francés. El viraje de la diplomacia gala explica esta falta de conclusión. El fin último seguía siendo la ocupación de Marruecos, presionado por el Ministerio de la Guerra, que habría remitido, a finales de 1902, su opinión en cuanto a una posible intervención francesa en el reino cherifiano. ${ }^{19}$

Dos años más tarde, el 8 de abril de 1904, París y Londres sellaron la entente cordial por la que ambos países se dejaban mutuamente el campo libre en Egipto y Marruecos. El artículo $8^{\circ}$ de dicho tratado reconocía los derechos españoles en el norte del reino alauita, pero nada decía respecto de una zona de influencia en el sur. Con la anuencia de Londres para que Francia tratara con España acerca del imperio marroquí, el ministro de Asuntos Exteriores galo se dispuso a recortar las zonas de influencia que habían sido adjudicadas a España en el tratado nonato de 1902, en compensación por la renuncia de los derechos franceses sobre Egipto en beneficio de Inglaterra.

moria. Revista de Historia Contemporánea, núm. 12, 2013, pp. 81-83, y Martínez Milán, España en el Sábara occidental..., op. cit., pp. 205-210.

${ }^{18}$ Antonio Niño, "Política de alianzas y compromisos coloniales para la 'regeneración' internacional de España, 1898-1914”, en Javier Tusell, Juan Avilés y Rosa Pardo (eds.), La política exterior de España en el siglo XX, Madrid, UNED-Biblioteca Nueva, 2000, pp. 31-94.

${ }^{19}$ Delaunay, Méfiance Cordiale..., op. cit., vol. 2, pp. 177-182. 
Las negociaciones, que se reanudaron el 19 de abril de 1904, culminaron el 3 de octubre con la firma del convenio hispanofrancés sobre Marruecos. El acuerdo -que permaneció secreto hasta noviembre de 1911, aunque no lo suficiente como para que Bernhard Heinrich Karl Martin von Bülow tuviera conocimiento de él un mes después de su firma- ${ }^{20}$ dividía y reducía la zona de influencia de España en la parte meridional en un territorio de soberanía (la Saqīa al-Hamrā); un enclave, el de Ifni, también de soberanía pero con unos límites bastante imprecisos, y una esfera de influencia en el sur del reino alauita cuyos límites eran los siguientes: el paralelo $24^{\circ} 40^{\prime}$ de latitud norte al sur, los meridianos $10^{\circ}$ y $11^{\circ}$ oeste de París al este, la línea divisoria, aproximadamente de las cuencas del Uād Sūs y Uād Nūn al norte, y el Océano Atlántico al oeste.

Más allá de la pérdida de territorios que se produjo tanto por el norte como por el este, lo más novedoso fue que la frontera septentrional de Río de Oro no había variado respecto a como quedó configurada en 1900, sino que había pasado de lindar con la zona de influencia española en el sur de Marruecos a limitar con una zona de soberanía como la Saqia al-Hamrā. A pesar de los recortes, el gobierno español lograba evitar que el retropaís canario cayera en manos de Francia u otra potencia, y mantener un nexo territorial entre sus posesiones a lo largo de una franja costera que se extendía desde el Uād Massa, al norte, hasta cabo Blanco, al sur. ${ }^{21}$

La reacción del káiser no se hizo esperar y, en un pulso a los gabinetes de la entente, éste desembarcó en Tánger el 31 de marzo de 1905 y dio paso así a la primera crisis marroquí, que trajo consigo la dimisión de Delcassé y la celebración de una conferencia para salir de esa crisis. Inaugurada en Algeciras, el 16 de enero, dos datos importantes se extraen: en primer lugar, que el reino de Marruecos, pese a todo, estaba condenado a perder su soberanía y, en segundo lugar, que la política internacional de España se insertaba, definitivamente, en la órbita

${ }^{20}$ Jean-Marc Delaunay apunta al ministro plenipotenciario español en Tánger, Bernardo de Cólogan, como la persona que comunicó a su homólogo alemán en dicha ciudad, Richard von Külhmann, las cláusulas del acuerdo secreto franco-español. Ibid., p. 209.

${ }^{21}$ Martínez Milán, España en el Sábara occidental..., op. cit., pp. 211-214. 
de la entente cordial, si bien supeditada, en el caso del reino cherifiano, al papel preponderante que juega Francia. ${ }^{22}$

La situación interior en el imperio cherifiano se había ido deteriorando a pasos agigantados desde 1906, resultado de la cada vez mayor dependencia financiera del Majzén de las grandes potencias, en especial de Francia, y de la injerencia extranjera. En febrero de 1909, Francia y el Imperio alemán llegaron a un acuerdo por el que la primera reconocía al segundo sus intereses económicos sobre Marruecos, a cambio de que el segundo le reconociera sus intereses políticos.

El 14 de enero de 1910, vulnerando lo acordado en Algeciras, el ministro de Asuntos Exteriores galo, Pichon, y los representantes enviados por el sultán, firmaron un acuerdo en París que aumentaba la dependencia económica y militar del Majzén respecto a Francia, y obligaba a Mulay Hafiz a remitir cartas a las autoridades del Sūs y del Nūn para advertirles de la necesidad de impedir el contrabando de armas y dinero a Mā al-'Aininn. Es más, el 4 de agosto, ambos gobiernos volvieron a firmar una convención, cuyo artículo diez hacía especial referencia al marabứ ${ }^{23}$ bidān y a la prohibición de hacerle llegar armas. Cuatro meses después de la firma del acuerdo y comprobando que Mulay Hafiz se había plegado a los intereses franceses, el "santón sahariano" se autoproclamó sultán y, acompañado por sus discípulos, hombres azules y beréberes de las llanuras y montañas del Sūs, marchó sobre Fez con objeto de derrocar al sultán; sin embargo, una columna francesa al mando del general Moinier lo derrotó en Tadla el 23 de junio de 1911. La re-

${ }^{22}$ Sobre la conferencia de Algeciras, véase José M. Allendesalazar, La diplomacia española y Marruecos, Madrid, Ministerio de Asuntos Exteriores, 1990, pp. 29-32; Francisco García Sanz, Historia de las relaciones entre España e Italia. Imágenes, comercio y política exterior (1800-1914), Madrid, Consejo Superior de Investigaciones Científicas, 1994, pp. 289-312; Víctor Morales Lezcano, León y Castillo, Embajador (1887-1918). Un estudio sobre la política exterior de España, Las Palmas de G. C., Cabildo Insular de Gran Canaria, 1975, pp. 99-104, y José A. González Alcantud y Eloy Martín Corrales (eds.), La conferencia de Algeciras en 1906: un banquete colonial, Barcelona, Bellaterra, 2007.

${ }^{23}$ Marabú (murabìt). Santo local, miembro fundador de un linaje o cofradía de personas dedicadas a la santidad. Una vez fallecido, su tumba o morabito se convertía en lugar de culto para sus seguidores. Algunos de estos santones, como fue el caso de Mā al'Ainīn en el Sahara occidental o el de Mohammed al-Sanūsī en el Sahara central y oriental, se levantaron contra la ocupación europea y proclamaron la yihad. Véase David Robinson y Jean-Louis Triaud (eds.), Le temps des marabouts. Itinéraires et stratégies islamiques en Afrique occidentale française, 1880-1960, París, Karthala, 1997. 
sistencia antifrancesa y la falta de ocupación de Río de Oro por los españoles venían preocupando al gobierno de París desde 1903, en especial al Ministerio de Colonias. Desde el mismo momento de la firma del Convenio franco-español, en 1900, pero sobre todo en los últimos años del primer decenio del siglo pasado, los coloniales habían buscado una nueva redelimitación de las fronteras no sólo más acorde con la realidad tribal, sino más ventajosa para la colonia de Mauritania con objeto de que la salvaguardara de las continuas razias provenientes de Río de Oro. Destaca, en este sentido, un informe elaborado por el coronel Patey, responsable de Mauritania, en marzo de 1911, que abogaba, bien por la cesión del Sahara o bien por subir la frontera sur del Sahara, estableciéndola en una línea que iría desde cabo Barbas (Océano Atlántico) hasta un punto en la frontera oriental en frente de la Sebja de Iyīl..$^{24}$

Sin embargo, el Quai d'Orsay siempre se opuso, basándose para ello en que este hecho no sólo daría lugar a nuevas reivindicaciones españolas en el Sahara, sino que cuestionaría también la delimitación de las respectivas zonas de influencia en Marruecos; y todo ello en un momento en el que Francia estaba decidida a "deshacerse" de su "socio" europeo en Marruecos, recortando al máximo posible la extensión de sus esferas de influencia tanto en el norte como en el sur.

La tensión diplomática entre Francia y España fue aumentando hasta alcanzar su punto culminante con los acontecimientos de mayo-junio de 1911: ocupación de Fez y Mequínez por los franceses, y Larache y Alcazarquivir por los españoles. La situación estaba a punto de internacionalizarse cuando Alemania intervino. A juicio de Jean-Marc Delaunay, fue la ocupación española la que provocó la "gran crisis marroquí de 1911 " ${ }^{25}$ El 27 de junio, y mientras se encontraba atracada en

${ }^{24}$ Archive Diplomatique du Ministère des Affaires Étrangères Paris, Nouvelle Série, Afrique Equatoriale Française, Contentieux territorial franco-espagnole, vol. vIII (mars 1907-janvier 1914), Note sur le Río de Oro, Saint Louis, le 11 mars 1911.

${ }^{25}$ Delaunay, Méfiance Cordiale..., op. cit., vol. 2, p. 463. Sobre la crisis de Agadir, véase también Jean Claude Allain, Agadir 1911. Une crise impérialiste en Europe pour la conquête du Maroc, París, Publications de la Sorbonne, 1976, y Jean Claude Allain, "La conferencia de Algeciras en la estrategia diplomática francesa a comienzos del siglo xx", en González Alcantud y Martín Corrales, La conferencia de Algeciras..., op. cit., pp. 51-72. 
el puerto de Santa Cruz de Tenerife, la segunda cañonera alemana que prestaba sus servicios en la colonia de Camerún (Panthersprung) recibió la orden de dirigirse a Agadir, a donde llegó el 1 de julio, dando paso así a la crisis de Agadir. Esta crisis obligó a Francia, una vez más, a sentarse en la mesa de negociaciones con Alemania. Como muy bien ha afirmado Jean Claude Allain, la demostración naval alemana ante el principal puerto marroquí del Sūs no tenía como fin desgajar de Marruecos esta provincia "para germanizarla", sino que fue en sí misma "un medio y no un fin". ${ }^{26}$

Cinco días más tarde, 6 de julio, el ministro de Estado español, García Prieto, comunicó al embajador alemán en Madrid que desde antes de junio el cónsul español en Mogador, Sostoa, había sido encargado de ocupar el lugar de Sidi Ifni, pero que la acción se había paralizado por la intervención alemana. Estaba claro que el objetivo de García Prieto era apoyarse en Alemania, sin que Francia ni Gran Bretaña tuvieran tiempo de reaccionar; algo, por otro lado, difícil de conseguir. Sabemos por el profesor Delaunay que los franceses convirtieron en objeto de sus reivindicaciones ante los alemanes la zona meridional de influencia española, pero excluyeron Ifni al considerarlo un territorio de soberanía y no de protectorado. No obstante, a finales de agosto, Justin de Selves, ministro galo de Asuntos Exteriores, indicó a su plenipotenciario en Tánger que comunicara al sultán la necesidad de que buscase la manera de lograr que los españoles renunciaran a Ifni a cambio de una extensión de territorio en los alrededores de Melilla.

$\mathrm{Si}$ se consiguiera "la desaparición de este enclave 'miserable', facilitaría enormemente la presión que ejerce Francia para ocupar todo el espacio del sur de Marruecos". ${ }^{27}$ Unos días después, el 2 de septiembre, hubo una reunión en San Sebastián entre García Prieto y los embajadores de Francia y Gran Bretaña en Madrid, en el que se insistía en que España abandonara la idea de una zona de influencia en el sur de Marruecos, a lo que García Prieto se negó.

${ }^{26}$ Allain, Agadir 1911..., op. cit., pp. 328-340.

27 “[...] la disparition de cette 'miserable' enclave, la pression française pour la mainmise sur tous les espaces sud-marocains serait grandement facilitée” (véase Delaunay, Méfiance Cordiale..., op. cit., p. 409. 
Además de la falta de apoyos externos, el gobierno presidido por Canaleja tuvo que hacer frente a otros problemas que surgieron durante ese verano tanto en Marruecos como en el interior del país: el inicio de la campaña del Kert, el motín del Numancia y la huelga revolucionaria de septiembre. Por si fuera poco, el 21 de septiembre, Gustavo de Sostoa informaba al ministro de Estado de la posibilidad de que el consulado francés en Mogador estuviera preparando una acción política en la zona de influencia española en el sur de Marruecos, con el fin de establecer la unión entre el Adrar y la costa de Tarfaya. ${ }^{28}$ Este hecho viene a añadirse a la secuencia de los acontecimientos reseñados arriba y es que la gran preocupación del Quai d'Orsay era reducir más que eliminar la zona meridional de influencia española, ya que estaban convencidos de que España tenía que compartir con ellos las compensaciones reclamadas por Alemania para reconocer el protectorado de ambas naciones en Marruecos. ${ }^{29}$

El 4 de noviembre de 1911, Kinderlen Wächter y Jules Cambon firmaron el convenio franco-alemán después de cuatro meses de movidas negociaciones. El acuerdo alcanzado dejaba plena libertad de acción a Francia en Marruecos, a cambio de la cesión de territorios en el Congo medio y en el Oubangui a la colonia alemana de Camerún.

A finales de noviembre, el representante español en Tánger, Villasinda, enviaba un telegrama a García Prieto en el que le comunicaba que el cónsul de Francia en Mogador negociaba "con los naturales principalmente de Uād Nūn. Objeto es desembarco tropas francesas entre el río Asaka y cabo Juby en el Buyda, atribuirse Tarfaya". ${ }^{30}$

García Prieto transmitió la información a su embajador en Londres, al tiempo que pedía a Pérez Caballero, embajador en París, que procurara obtener alguna información ante de Selves. Mientras los ingleses alegaban ignorar este asunto, el 2 de diciembre, Villasinda comunicaba al ministro de Estado que el

\footnotetext{
${ }^{28}$ AGAP, África, Marruecos, caja 152, exp. 1, despacho 1389, El representante español en Tánger a Ministro de Estado, Tánger, 27 de septiembre de 1911.

${ }^{29}$ Allain, Agadir 1911..., op. cit., p. 415, y Martínez Milán, España en el Sábara Occidental..., op. cit., pp. 219-220.

${ }^{30}$ AGAP, África, Marruecos, caja 152, exp. 1, telegrama cifrado, Villasinda a Marqués de Albucemas, Tánger, 30 de noviembre de 1911.
} 
cónsul francés apremiaba a los jefes de las tribus del Uād Nūn para que firmasen un convenio que facilitase el desembarco de tropas francesas. Cinco días antes, el 27 de noviembre, había tenido lugar una reunión en los jardines del consulado francés a la que asistieron, por una parte, los comisionados galos Boulle y Fleury y, por la otra, los indígenas de Ayt Yemel: el cheij Brahìm uld Embarek y Sidi Mohamed uld Belal, de la cabila Izargiyyīn, y un representante de los ahel Beirūk. El motivo de la reunión era firmar un tratado que facilitara el desembarco de tropas en el Buida (cerca del río Asaka) y en Ajfnir (Tarfaya), y su tránsito hacia Smara; sin embargo, los indígenas se negaron pues argumentaron que necesitaban pensarlo. ${ }^{31}$ No era la primera vez que los ahel Beirūk y los franceses se ponían en contacto, aunque la razón que impulsaba a Beirūk en estos primeros años del siglo xx era diferente: la rivalidad con los ahel $\mathrm{Ma}$ al-'Ainīn como consecuencia de la influencia que ejercían entre los nómadas Tekna.

García Prieto ordenó al embajador español que Sostoa empleara todos los medios a su alcance para contrarrestar la acción política de su homólogo francés, e insistió a Pérez Caballero para que se lamentara de tal actitud ante el responsable del Quai d'Orsay. En nuestra opinión, la actitud francesa no obedecía solamente a un interés por compensar la pérdida de los territorios subsaharianos cedidos a Alemania, con buena parte de la zona de influencia española en el sur de Marruecos, sino también al intento de acabar con uno de los focos de resistencia a la penetración francesa en el Magreb más importantes de los años previos a 1914: el acaudillado por Mā al-'Ainīn y, posteriormente, por su hijo Ahmed al-Haiba. ${ }^{32}$ La crisis de Agadir, concluye Delaunay, fue "la consecuencia de una crisis de desconfianza franco-española mal interpretada por el Imperio alemán, que ignoró hasta el otoño la naturaleza exacta de las relaciones entre los dos países encargados de la vigilancia de Marruecos". ${ }^{33}$

${ }^{31}$ AGAP, África, Marruecos, caja 152, exp. 1, telegrama cifrado, Villasinda a García Prieto, Tánger, 4 de diciembre de 1911; y despacho 1.756, Ministro plenipotenciario de España en Tánger a Ministro de Estado, Tánger, 16 de diciembre de 1911.

${ }^{32}$ Martínez Milán, España en el Sábara occidental..., op. cit., pp. 221-222.

33 “[...] la conséquence d'une crise de défiance franco-espagnole mal interprétée par le Reich qui ignorait jusqu'à l'automne la nature exacte [...] des relations entre 
A principios de 1911 comenzaron los primeros contactos hispano-franceses que desembocarían, once meses más tarde, en el establecimiento del protectorado hispano-francés sobre Marruecos. Nada más iniciarse las conversaciones, el Quai d'Orsay presentó un anteproyecto de tratado en el que la zona meridional de influencia española más el territorio de la Saquīa alHamrā pasaban a manos francesas, propuesta que fue rechazada por el ministro de Estado.

En enero de 1912 caía Caillaux al frente del ejecutivo francés y era sustituido por Poincaré. El mes siguiente, Alfonso XIII mantuvo una entrevista con el agregado militar galo en Madrid, al que le comentó la posibilidad de aceptar la propuesta francesa si París accedía a reconocer a España una zona de influencia en el sur de Marruecos, en frente de Canarias, aunque fuera reducida en comparación con la otorgada por el convenio de 1904. La respuesta fue que sólo estaban dispuestos a conceder la Saquīa al-Hamrā. El gabinete de Canalejas rechazó esta contraoferta y el 14 de marzo hizo saber a Poincaré que quería una zona de influencia en Marruecos entre el paralelo 270 40' y el Uād Drā, además de un trecho de costa, que se extendiera hacia el norte hasta llegar al límite meridional de Ifni. A lo que Francia, naturalmente, se opuso. Ante este diálogo de sordos, Gran Bretaña, que actuaba de mediador, presionó a Francia para que llegara a un acuerdo sobre la zona meridional. Resultado de ello fue la propuesta de una nueva delimitación por la cual se respetaba el párrafo segundo del artículo $6^{\circ}$ del convenio de 1904, y el territorio de Ifni. A cambio, París pedía una redelimitación de la citada zona, ajustándola al territorio comprendido entre el paralelo $27^{\circ} 40^{\prime}$ hasta su intersección con el meridiano $11^{\circ}$ oeste de París, y por este meridiano hasta el Uād Drā, con lo que se rompía la continuidad territorial entre la futura zona sur e Ifni. A pesar de ello, la propuesta fue aceptada por el gobierno de Canalejas el 10 de abril. ${ }^{34}$

les deux pays chargés de la police du Maroc" (véase Delaunay, Méfiance Cordiale..., op. cit., vol. 2, p. 464).

${ }^{34}$ Véanse: Frank E. Trout, Morocco's Saharan Frontiers, Ginebra, Droz Publisher, 1969, pp. 205-210; José M. de Areilza y Fernando M. Castiella, Reivindicaciones de España, Madrid, Instituto de Estudios Políticos, 1945, pp. 589-596 Edouard Rouard, Traites et Accords concernant le Protectorat de la France au Maroc, París, A. Pedone, 1914, pp. 62-66, y Delaunay, Méfiance Cordiale..., op. cit., vol. 2, pp. 465-573. 
Un día antes, el 9 de abril, el ministro plenipotenciario español en Tánger había remitido un despacho a García Prieto en el que le comunicaba que emisarios de al-Haiba se habían presentado a Sostoa para pedirle el apoyo de España ante la sublevación contra Mulay Hafid. La respuesta de Madrid despejaba cualquier duda al respecto: "estimo - escribe el ministro de Estado- no podemos adoptar actitud sugerida por Cónsul Mogador (apoyarles), pues en principio hemos aceptado [...] que el norte del Drá, excepto Ifni y territorio adyacente, pase a ser zona francesa" ${ }^{35}$ Catorce días después, Gustavo de Sostoa advertía a Villasinda que si el gobierno se decidía a ocupar "su zona sur más o menos mutilada" era necesario contar con el hijo de Mā al-'Ainīn. ${ }^{36}$ Ante este hecho, el ministro de Estado modificó algo su actitud inicial e indicó a Villasinda que el cónsul en Mogador estableciera "tan amistosas relaciones como fueran posible" con al-Haiba. ${ }^{37}$ Aunque el gobierno español intentó meses después aprovechar la situación creada por la abdicación de Mulay Hafid para tratar de ocupar Sidi If́ni, lo cierto es que el 27 de noviembre de 1912, Louis Geoffray y García Prieto firmaban, en Madrid, el convenio hispano-francés sobre Marruecos. De los 27 artículos que componían el convenio, el segundo y el tercero hacían referencia a la delimitación territorial de ambas zonas del protectorado. Respecto a la zona meridional, la importancia no residía tanto en la reducción territorial frente al convenio de 1904, como en la fractura territorial de las posesiones españolas entre cabo Blanco y el Uād bu Sedra que permitió a Francia tomar asiento entre Ifni y Tarfaya.

\section{Conclusiones}

Desde 1875 en adelante, España siempre estuvo atenta a cualquier establecimiento o intento de asentamiento europeo entre

\footnotetext{
${ }^{35}$ AGAP, África, Marruecos, caja 152, exp. 1, telegrama cifrado, Ministro de Estado a Ministro plenipotenciario español en Tánger, Madrid, 12 de abril de 1912.

${ }^{36}$ AGAP, África, Marruecos, caja 152, exp. 1, despacho 693, Villasinda a Ministro de Estado, Tánger, 23 de abril de 1912.

${ }^{37}$ AGAP, Africa, Marruecos, caja 152, exp. 1, telegrama cifrado, García Prieto a Ministro Plenipotenciario en Tánger, Madrid, 28 de abril de 1912.
} 
las regiones del Sūs y cabo Blanco. Esta atención se tornó en recelo hacia Francia, cuando ésta intentó aprovechar el descontento de las cabilas de la región para implantar un protectorado que chocaba con los intereses hispanos en la región. Ese recelo se convirtió en malestar, a la vez que en temor, cuando en el convenio hispano-francés de 1900, España no pudo incluir dentro de sus posesiones saharianas el Adrar Tmar ni definir en favor de sus intereses la frontera norte del protectorado de Río de Oro. Ello movió a Silvela a intentar cerrar un acuerdo con Marruecos, primero, y con Londres y París, después, para que el sultán aceptara un intercambio de Ifni por Tarfaya que concluyó en un fracaso rotundo. En los dos primeros años del siglo xx hubo un periodo de complacencia que fracasó porque no se firmó el tratado nonato de 1902. Por ese tratado, España conseguía en el sur de Marruecos un espacio de terreno que nunca soñó poseer. Más allá de cuál fue la causa real que impidió su firma, lo cierto es que este hecho supuso un varapalo a las pretensiones hispanas en el sur de Marruecos. A partir de ese momento, Madrid quedó a merced de los movimientos que Francia realizó en la escena internacional en relación con el país alauita y que tantas ampollas levantaron en los gabinetes de la Restauración y en buena parte de la opinión pública nacional. Una vez que Francia y Reino Unido se repartieron sus zonas de influencia en el norte de África, en 1904, París se propuso hacer pagar a Madrid, con recortes territoriales en el sur del reino cherifiano, el desentendimiento galo de Egipto. La zona de influencia española en el convenio franco-español de 1904 no sólo fue recortada, sino dividida entre territorios de soberanía y esferas de influencia.

La tensión entre ambos países se fue acrecentando entre 1904 y 1911 -entre otros motivos por la falta de ocupación de Río de Oro, que se había convertido en el centro de la resistencia contra la penetración francesa en Mauritania- hasta que la crisis de Agadir lo cortó de raíz. Tras el acuerdo francoalemán, París decidió suprimir la zona de influencia española en el sur de Marruecos, excepto Ifni. A pesar de la resistencia de Madrid frente a los intentos franceses, e ingleses al principio, para que aceptara "el hecho consumado", fue la intervención británica la que, ante una posible ruptura de las negociaciones 
y el viraje de Madrid hacia Berlín, permitió que París aceptara una pequeña zona de influencia hispana en sur del reino cherifiano, lo que quedó plasmado en la convención que ambos países firmaron el 27 de noviembre de 1912.

Dirección institucional del autor:

Departamento de Ciencias Históricas

Facultad de Economía, Empresa y Turismo

C/Saulo Torón, 4

Las Palmas de Gran Canaria

35017, España

凶jesus.martinez@ulpgc.es

\section{Bibliografía}

Allain, Jean Claude, Agadir 1911. Une crise impérialiste en Europe pour la conquête du Maroc, París, Publications de la Sorbonne, 1976.

Allain, Jean Claude, "La conferencia de Algeciras en la estrategia diplomática francesa a comienzos del siglo xx", en José A. González Alcantud y Eloy Martín Corrales (eds.), La conferencia de Algeciras en 1906: un banquete colonial, Barcelona, Bellaterra, 2007, pp. 51-72.

Allendesalazar, José M., La diplomacia española y Marruecos, Madrid, Ministerio de Asuntos Exteriores, 1990.

AreIlza, José M. de y Fernando M. Castiella, Reivindicaciones de España, Madrid, Instituto de Estudios Políticos, 1945.

Delaunay, Jean-Marc, Méfiance Cordiale. Les relations coloniales franco-espagnoles de la fin du XIXe siècle à la Première Guerre mondiale, París, L'Harmattan, 2010.

GARCía SANZ, Francisco, Historia de las relaciones entre España e Italia. Imágenes, comercio y política exterior (1800-1914), Madrid, Consejo Superior de Investigaciones Científicas, 1994.

GeLLNER, Ernest, Saints of the Atlas, Londres, Weidefeld \& Nicolson, 1969.

GeLlNER, Ernest, Cultura, identidad y política. El nacionalismo y los nuevos cambios sociales, Barcelona, Gedisa, 2003.

Gellner, Ernest y Valensi Lucette, "Pouvoir politique et fonction religieuse dans l'Islam marocain”, Annales. Economies, Sociétés, Civilisations, núm. 3, 1970, pp. 699-713. 
González Alcantud, José A. y Eloy Martín Corrales (eds.), La conferencia de Algeciras en 1906: un banquete colonial, Barcelona, Bellaterra, 2007.

HART, David M., "The Ait Ba 'Amran of Ifni: An Ethnography Survey", Revue de l'Occident musulman et de la Méditerranée, núm. 15-16, 1973, pp. 61-74.

HART, David M., Estructuras tribales precoloniales en Marruecos Bereber, 1860-1933: una reconstrucción etnográfica en perspectiva bistórica, Granada, Universidad de Granada, 1997.

Le Chatelier, Alfred, Tribus du sud-ouest marocain. Bassins côtiers entre Sous et Draa, París, Ernest Laroux, 1891.

MarTínEZ Milán, Jesús M., "El colonialismo español en el Sáhara occidental y en la zona sur del Protectorado español en Marruecos, 1885-1945", tesis de doctorado en historia contemporánea, Madrid, Universidad Nacional de Educación a Distancia, 2000.

Martínez Milán, Jesús M., "Los establecimientos y proyectos extranjeros en la costa de África frontera a Canarias en el último cuarto del siglo XIX, y los intereses españoles en la zona", en Hassan Bagri y Antonio Tejera Gaspar (coords.), Marruecos y Canarias. Miradas cruzadas, Rabat, Publicaciones de la Facultad de Letras y Ciencias Humanas de la Universidad Ibn Zohr, 2000, pp. 153-169.

MARTínez Milán, Jesús M., España en el Sábara occidental y en la zona sur del protectorado en Marruecos, Madrid, UNED Ediciones, 2003.

Morales LezCano, Víctor, León y Castillo, Embajador (1887-1918).

Un estudio sobre la política exterior de España, Las Palmas de G. C., Cabildo Insular de Gran Canaria, 1975.

NAIMI, Mustapha, "La rive sud saharienne de 1842 à 1872 dans les registres comptables de la famille Bayruk (l'apport de trois nouvelles sources)", ponencia presentada en el Colloque sur les Sources Arabes de l'Histoire Africaine, Commission Internationale pour une Histoire Scientifique et Culturelle de l'Humanité, Rabat, 1-3 de abril de 1987, s. 1., Commission for a Scientific and Cultural History of Mankind, 1987.

Naimi, Mustapha, "Le pouvoir Makhzen dans le Souss", Revue Maroc Europe. Histoire, Economies, Sociétés, núm. 6, 1994, pp. 85-94.

NaImi, Mustapha, La dynamique des alliances ouest-sabariennes : de l'espace géographique à l'espace social, París, Maison de Sciences de l'Homme, 2004.

NiÑo, Antonio, "Política de alianzas y compromisos coloniales para la 'regeneración' internacional de España, 1898-1914”, en Javier Tusell, Juan Avilés y Rosa Pardo (eds.), La política exterior de Es- 
paña en el siglo XX, Madrid, UNED-Biblioteca Nueva, 2000, pp. 3194.

Pascon, Paul y Mohammed Ennaji, Le Makhzen et le Sous Al-Aqsa. La correspondance politique de la maison d'Iligh (1821-1894), ParísCasablanca, CNRs-Toukbal, 1988.

Pastor Garrigues, Francisco M., "España y la apertura de la cuestión marroquí (1897-1904)", tesis de doctorado, Valencia, Universidad de Valencia-Servei de Publicacions, 2006.

Pastor Garrigues, Francisco M., "Marruecos, campo de batalla de los imperialismos europeos en el siglo XIX: la guerra de espías francoespañola en el Sūs en 1886-1887", Awrāq. Estudios sobre el mundo árabe e islámico contemporáneo, vol. xxv, 2008, pp. 143-150.

Pastor Garrigues, Francisco M., "Las veleidades saharianas del gobierno Silvela (1900)”, Mélanges de la Casa de Velázquez, tomo 411, 2011, pp. 211-231.

Pastor Garrigues, Francisco M., “Antonio Maura y el papel del in Reich en las negociaciones francesas sobre Marruecos de 19031904", Pasado y Memoria. Revista de Historia Contemporánea, núm. 12, 2013, pp. 79-108.

RoBINsOn, David y Jean-Louis Triaud (eds.), Le temps des marabouts. Itinéraires et stratégies islamiques en Afrique occidentale française, 1880-1960, París, Karthala, 1997.

ROUARD, Edouard, Traites et Accords concernant le Protectorat de la France au Maroc, París, A. Pedone, 1914.

TORRE DEL Río, Rosario de la, "El factor colonial en la política exterior española 1789-1898", en I Encuentro Peninsular de Historia de las Relaciones Internacionales, Zamora, Asociaçao Portuguesa de Historia das Relaçoes Internacionales-Comisión Española de Historia de las Relaciones Internacionales-Fundación Rei Afonso Henriques, 1998, pp. 245-264.

Trout, Frank E., Morocco's Saharan Frontiers, Ginebra, Droz Publisher, 1969. 
